\title{
Impact of Board-Certified Cardiologist Characteristics on Risk of In-Hospital Mortality
}

\author{
Mika Watanabe, MD; Kihei Yoneyama, MD, PhD; Michikazu Nakai, PhD; \\ Koshiro Kanaoka, MD, PhD; Satoshi Okayama, MD, PhD; Kunihiro Nishimura, MD, PhD; \\ Yoshihiro Miyamoto, MD, PhD; Masaki Izumo, MD, PhD; Yuki Ishibashi, MD, PhD; \\ Takumi Higuma, MD, PhD; Tomoo Harada, MD, PhD; Satoshi Yasuda, MD, PhD; \\ Toyoaki Murohara, MD, PhD; Yoshihiko Saito, MD, PhD; Yoshihiro J. Akashi, MD, PhD
}

\begin{abstract}
Background: This study examined the influence of board-certified cardiologist characteristics on the in-hospital mortality of patients with cardiovascular disease.

Methods and Results: Data were collected between 2012 and 2014 from a nationwide database of acute care hospitals in Japan. Overall, there were $1,422,703$ patients, of whom 883,746 were analyzed. The primary outcome was all-cause in-hospital mortality. The association between board-certified cardiologist characteristics and in-hospital mortality was estimated using multilevel mixed-effect logistic regression modeling. Median age of cardiologists in a hospital was not related to in-hospital mortality $(\mathrm{OR}, 1.003 ; 95 \% \mathrm{Cl}$ : 0.998-1.008, $\mathrm{P}=0.316$ ), but a greater cardiologist age range was associated with a lower risk of in-hospital mortality (OR, 0.992; 95\% $\mathrm{Cl}$ : $0.988-0.995$ per 1 -unit increment in age range, $\mathrm{P}<0.001)$. Meanwhile, the average years of experience of the board-certified cardiologists in a hospital was not associated with a lower risk of in-hospital mortality (OR, 1.002; 95\% Cl: 0.996-1.007, $\mathrm{P}=0.525)$, but a greater range of years of experience was (OR, $0.986 ; 95 \% \mathrm{Cl}: 0.983-0.990$ per 1-unit increment in range of years of experience, $\mathrm{P}<0.001)$.
\end{abstract}

Conclusions: Median board-certified cardiologist age/experience at an institution is not related to in-hospital mortality, but a greater range in age/experience is associated with a lower risk of mortality.

Key Words: Board-certified cardiologist; Cardiovascular disease; In-hospital mortality

$\mathbf{R}$ ecent advancements in the treatment of cardiovascular disease (CVD) have resulted in substantial decreases in related mortality rates. ${ }^{1,2}$ CVD, however, still causes 17.9 million deaths every year, corresponding to $31 \%$ of all deaths worldwide. Further, according to World Health Organization projections, the worldwide CVD-related burden will reach 47 million disability adjusted life years (years lost due to disability, ill-health, or death) by $2020 .^{2}$

The expanded use of medical therapies is increasing the quality of cardiac medical care, and hopefully decreasing mortality rates. ${ }^{36}$ Board-certified physicians are skilled, knowledgeable experts in their specialty, and practice a higher standard of medicine in their fields. Patients who are hospitalized as a result of CVD have been found to receive better care from cardiologists than from physicians who specialize in other disciplines, ${ }^{7-9}$ but no study has yet investigated the influence that board-certified physicians have on patient prognosis.

In this study, using the Japanese Registry of all Cardiac and Vascular Diseases (JROAD), we examined the relationship between the characteristics (e.g., age and years of experience) of hospital board-certified cardiologists and the hospitals' respective patient outcomes. JROAD is a nationwide database that stores data concerning hospital and patient characteristics, principal diagnoses, comorbidities at admission, complications after admission, procedures during hospitalization, and discharge status.

Received August 2, 2019; revised manuscript received October 24, 2019; accepted October 31, 2019; J-STAGE Advance Publication released online December 13, 2019 Time for primary review: 1 day

Division of Cardiology, Department of Internal Medicine, St. Marianna University School of Medicine, Kawasaki (M.W., K.Y., M.I., Y.I., T. Higuma, T. Harada, Y.J.A.); National Cerebral and Cardiovascular Center, Suita (M.N., K.N., Y.M., S.Y.); Department of Cardiovascular Medicine, Nara Medical University, Kashihara (K.K., S.O., Y.S.); and Department of Cardiology, Nagoya University Graduate School of Medicine, Nagoya (T.M.), Japan

Y.M., S.Y., T.M., and Y.J.A. are members of Circulation Reports' Editorial Team.

ORCiDID: 0000-0001-7670-7326

Mailing address: Yoshihiko Akashi, MD, PhD, Division of Cardiology, Department of internal Medicine, St. Marianna University School of Medicine, 2-16-1 Sugao, Miyamaeku, Kawasaki 216-8511, Japan. E-mail: yoakashi-circ@umin.ac.jp

ISSN-2434-0790 All rights are reserved to the Japanese Circulation Society. For permissions, please e-mail: cr@j-circ.or.jp 
A

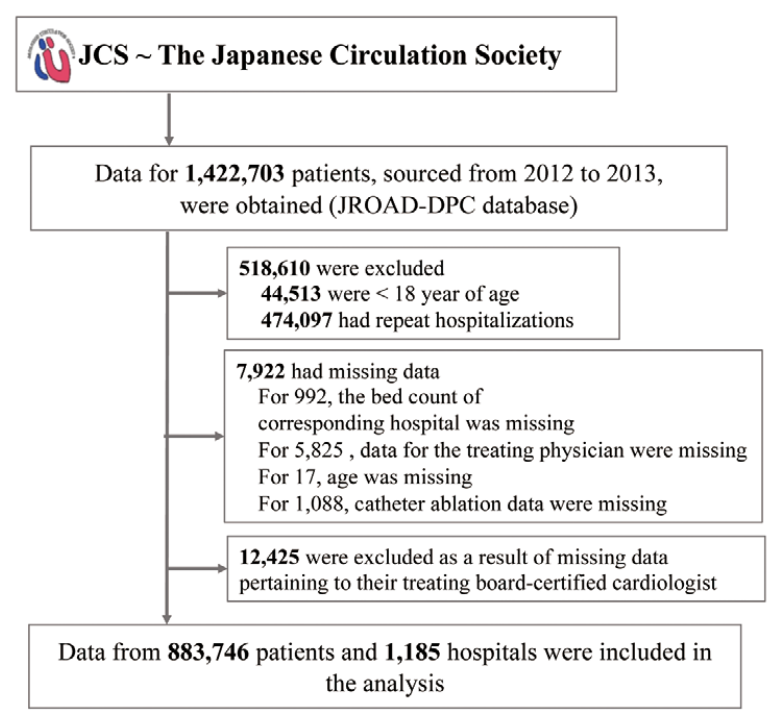

B

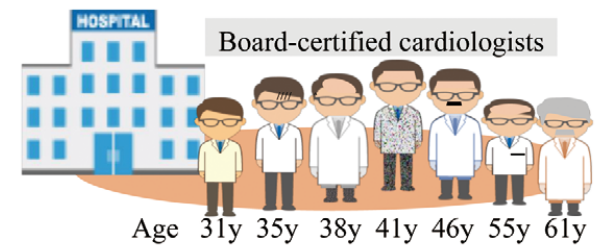

Years of experience $1 y \quad 3 y \quad 3 y \quad 5 y \quad 9 y \quad 15 y \quad 20 y$

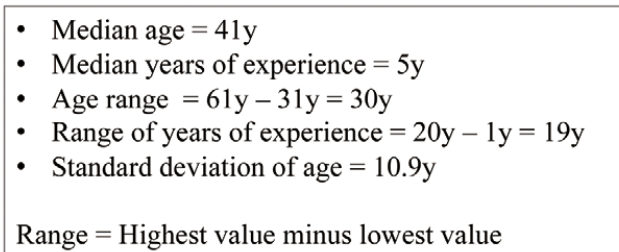

- Median age $=41 \mathrm{y}$

- Age range $=61 \mathrm{y}-31 \mathrm{y}=30 \mathrm{y}$

Age range $=61 \mathrm{y}-31 \mathrm{y}=30 \mathrm{y}$

Standard deviation of age $=10.9 \mathrm{y}$

Range $=$ Highest value minus lowest value

Figure 1. Flow chart of subject selection. Almost all diagnostic procedure combination (DPC) hospitals with cardiovascular beds meet the Japanese Circulation Society (JCS) requirements. All training hospitals and hospitals associated with JCS must provide institutional data (hospital bed count, number of board-certified cardiologists etc.) and DPC hospitals must also provide patient data (age, gender, International Classification of Diseases and Injuries 10th revision codes etc.). JROAD, Japanese Registry of all Cardiac and Vascular Diseases.

\section{Methods}

\section{Patient and Public Involvement}

The JROAD database is a nationwide prospective registry that was designed to assess the clinical activity of every Japanese institution that provides cardiovascular care, and to provide adequate feedback to teaching hospitals regarding improving patient care. A detailed description of the database's design and methods has previously been published. ${ }^{9-11}$ Briefly, however, the JROAD database, which has stored demographic information for every hospital since 2004, and the JROAD-DPC nationwide database, which has stored data pertaining to the Japanese Diagnosis Procedure Combination/Per Diem Payment System (DPC/PDPS) since 2012, were developed by the Japanese Circulation Society (JCS). The DPC database is a mixed-case classification system linked with a lump-sum payment system, and was launched in 2002 by the Ministry of Health, Labour and Welfare of Japan.12 Compared with other registry databases, the DPC database enables researchers to conduct nationwide studies of both descriptive and/or analytical epidemiology in real-world clinical settings. The DPC database includes data on the following elements: patient demographics (e.g., age and gender); principal diagnosis (coded according to the International Classification of Diseases and Injuries, 10th revision; ICD-10); comorbidities at admission (ICD-10 coded); complications after admission (ICD-10-coded); procedures, including surgery, medication, and devices used during hospitalization; length of stay; discharge status; and medical expenses. ${ }^{10,12-14}$ A wide variety of centers, including academic, urban, and rural hospitals, use the DPC system. ${ }^{10,15}$

Considering the aforementioned characteristics of the JROAD-DPC database, we considered it to be an ideal source for the present research topic: namely, the effects of the characteristics of board-certified cardiologists on patient outcome.

All data obtained for this study from the JROAD database concerned hospitalized patients with clinically apparent CVD. This research was approved by the institutional review board of St. Marianna University School of Medicine (registration no. 3419). Further, all patient data were anonymized, given that each hospital used code-change equations to encrypt patient IDs in the database. Individual data (including age, gender, and hospital bed count) were sent to the JROAD data center using an electronic data capture system or recordable compact disc.

\section{Study Design and Sampling}

We conducted a cross-sectional study using both the JROAD and JROAD-DPC databases, recording entries made in the databases between 1 April 2012 and 31 March 2014. A total of 2,407 hospitals are included in the JROAD database and, of these, 1,247 (52\%) have adopted the DPC system and have agreed to participate in the JROAD-DPC database project (Figure 1). The characteristics of hospitals that did provide JROAD-DPC data and those that did not, along with the ICD-10 diagnosis codes, have been summarized in a previous study. ${ }^{10}$ A total of 1,422,703 consecutive patients were initially included in this study, but 538,957 patients were later excluded because of missing data, being $<18$ years of age with no pediatrician data, or having a history of prior hospitalization. Patients who had no missing variables were included in the analyses $(n=883,746)$.

Data for board-certified cardiologists were collected from JCS. According to the JCS website (http://www.j-circ. or.jp/information/senmoni/index.htm), board-certified 


\begin{tabular}{|c|c|}
\hline & $\begin{array}{l}\text { Nationwide } \\
\text { database }\end{array}$ \\
\hline \multicolumn{2}{|l|}{ Patient demographics $(n=883,746)$} \\
\hline Age (years) & $73(64-81)$ \\
\hline Male gender & $547,558(62)$ \\
\hline \multicolumn{2}{|l|}{ Cardiovascular disease } \\
\hline Angina & $233,404(26)$ \\
\hline Acute MI & $46,922(5)$ \\
\hline Heart failure & $145,431(16)$ \\
\hline Aortic disease & $72,058(8)$ \\
\hline Pulmonary embolism & $6,073(0.7)$ \\
\hline Atrial fibrillation or flutter & $46,645(5)$ \\
\hline Cardiac arrest & $52,155(6)$ \\
\hline \multicolumn{2}{|l|}{ Coexisting condition } \\
\hline Charlson comorbidity index & $1(0-2)$ \\
\hline \multicolumn{2}{|l|}{ Outcome } \\
\hline In-hospital death rate & $102,667(13.2)$ \\
\hline \multicolumn{2}{|l|}{ Facility demographics $(n=1,185)$} \\
\hline No. hospital beds & $476(334-646)$ \\
\hline Cardiac surgery facility & $710,631(80)$ \\
\hline No. board-certified cardiologists & $5(4-9)$ \\
\hline \multicolumn{2}{|l|}{ No. hospitals with: } \\
\hline$<300$ beds & $143,621(16)$ \\
\hline $300-449$ beds & $254,721(29)$ \\
\hline $450-749$ beds & $347,679(39)$ \\
\hline$>749$ beds & $137,725(16)$ \\
\hline \multicolumn{2}{|l|}{$\begin{array}{l}\text { Board-certified cardiologist demographics } \\
(n=14,276)\end{array}$} \\
\hline Age (years) & $47(41-55)$ \\
\hline Male & $12,747(89)$ \\
\hline Years of experience (years) & $9(4-17)$ \\
\hline Age range per hospital (years) & $33(32-65)^{\dagger}$ \\
\hline $\begin{array}{l}\text { Range of years of experience per hospital } \\
\text { (years) }\end{array}$ & $23(0-23)^{\dagger}$ \\
\hline
\end{tabular}

Data given as $\mathrm{n}(\%)$, median (IQR) or tmedian (range). MI, myocardial infarction.

cardiologists must (1) be regular members of the JCS for a minimum of 6 years; (2) be board-certified members of the Japanese Society of Internal Medicine, the Japan Surgical Society, the Japan Pediatric Society, the Japanese Association of Thoracic Surgery, or the American Society of Internal Medicine; (3) have completed 3 years of training at a certified institution; and (4) have passed the board certification examination offered by the JCS. Years of experience was calculated as the difference between the year we sourced the data (2012 or 2013) and the year the individual in question became a board-certified cardiologist.

Each hospital annually confirms the certifications of their board-certified cardiologists, but only records in the JROAD database the total number of board-certified cardiologists employed by the hospital (i.e., no identifying information is provided); this means that we were unable to create a merged dataset through which we could identify which physician was responsible for treating which patients.

For each hospital, the number of non-board-certified cardiologists per year was defined as the total number of cardiologists at a given hospital minus the number of board-certified cardiologists at the hospital. Finally, the ratio of beds to board-certified cardiologists was calculated by dividing the number of beds per hospital by the number of board-certified cardiologists for that same hospital. A higher index represents a greater number of beds per board-certified cardiologist.

\section{Outcome}

The primary outcome was the occurrence of in-hospital mortality for any cause (i.e., not necessarily cardiac related). This was possible because JROAD-DPC data can provide a relatively complete perspective of mortality during hospitalization.

\section{Statistical Analysis}

For each hospital, board-certified cardiologist age, years of experience, and the range of each of these characteristics were divided into quartiles. If patients were hospitalized more than once during the study period, we used only the data associated with the last admission, while recording the total number of prior hospitalizations. To assess the association between the characteristics of the board-certified cardiologists and in-hospital mortality, we used multilevel mixed-effects logistic regression models to estimate the odds ratios (OR) for in-hospital mortality. Each of the multilevel mixed-effects logistic regression model variables included a hierarchy level (hospital) that considered the random effects of hospital variation. All estimates were adjusted for hospital demographics (number of boardcertified cardiologists, board-certified cardiologist gender, number of non-board-certified cardiologists, number of hospital beds, number of coronary care units, cardiac surgery facility, 8 regional divisions of Japan), patient demographics (patient age, gender, Charlson comorbidity index, and incidence rates of angina pectoris, myocardial infarction, atrial fibrillation, heart failure, aortic disease, cardiac arrest, pulmonary thromboembolism, primary pulmonary hypertension, tetralogy of Fallot, incident pneumonia during hospitalizations, and number of prior hospitalizations), and patient therapy (percutaneous coronary intervention, coronary artery bypass grafting, catheter ablation, implantable cardioverter defibrillator, and cardiac resynchronization therapy). The adjusted probabilities of in-hospital mortality were calculated in STATA using marginsplot, after the multilevel mixed-effects logistic regression analysis. All analyses were performed using STATA version 14 (Stata Corp, College Station, TX, USA).

\section{Results}

\section{Patient, Facility, and Cardiologist Characteristics}

The final study sample consisted of 883,746 patients with CVD who were admitted to DPC-participating hospitals. Both clinical presentation and facility characteristics are listed in Table 1. Overall, average patient age was 73 years, and $62 \%$ were male. The most common CVD were angina $(26 \%)$, heart failure $(16 \%)$, aortic disease $(8 \%)$, and myocardial infarction $(5 \%)$. Meanwhile, the median bed count of the institutions was 476, and the mean number of boardcertified cardiologists per institution was 5 . The average age of the board-certified cardiologists was 47 years, and $89 \%$ were male; meanwhile, average years of experience was 9. The average age range of the board-certified cardiologists per institution was 33 years (range, 32-65 years), while the average range of years of experience was 23 years (range, $0-23$ years). 
Table 2. Cardiologist Board Certification and In-Hospital Death

In-hospital death

(No. events: 102,667/883,746)

Board-certified cardiologists

\begin{tabular}{|c|c|c|c|}
\hline Age (years) & $1.003(0.998-1.008)^{\dagger \dagger}$ & $1.006(1.001-1.010)^{*}$ & $1.006(1.001-1.011)^{\star}$ \\
\hline Age range (years) & $0.993(0.990-0.996)^{\star \star *}$ & $0.991(0.988-0.994)^{\star \star *}$ & $0.992(0.988-0.995)^{\star * *}$ \\
\hline SD of age (years) & $0.991(0.982-1.000)$ & $0.989(0.98-0.997)^{*}$ & $0.990(0.982-0.999)^{*}$ \\
\hline \multicolumn{4}{|c|}{ Years of experience as board-certified cardiologists } \\
\hline Years of experience (years) & $0.996(0.99-1.002)$ & $1.002(0.996-1.007)$ & $1.002(0.996-1.007)$ \\
\hline Range of years of experience (years) & $0.983(0.979-0.987)^{\star \star \star}$ & $0.986(0.982-0.990)^{\star \star \star}$ & $0.986(0.983-0.990)^{\star * *}$ \\
\hline SD of years of experience & $0.976(0.965-0.986)^{\star \star \star}$ & $0.982(0.972-0.991)^{\star * *}$ & $0.982(0.973-0.992)^{\star * *}$ \\
\hline
\end{tabular}

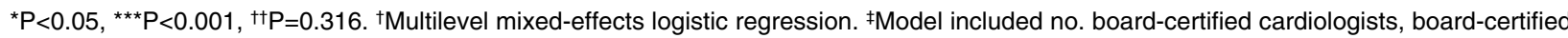
cardiologist gender, no. non-board-certified cardiologists, no. hospital beds, no. coronary care units, cardiac surgery facility, 8-region division. sModel included, in addition to the facility model, patient age, gender, Charlson comorbidity index, and incidence of angina pectoris, myocardial infarction, atrial fibrillation, heart failure, aortic disease, cardiac arrest, pulmonary thromboembolism, primary pulmonary hypertension, tetralogy of Fallot, and incident pneumonia during hospitalizations. It also included no. prior hospitalizations. "Model included, in addition to the clinical characteristics model, percutaneous coronary intervention, coronary artery bypass grafting, catheter ablation, implantable cardioverter defibrillators, and cardiac resynchronization therapy.

A

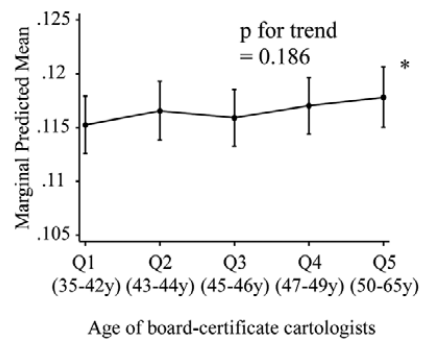

$\mathrm{D}$

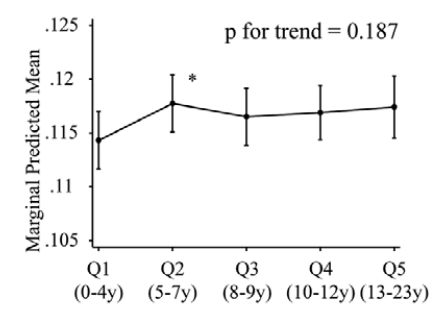

Years of experience as board-certified cardiologists
B

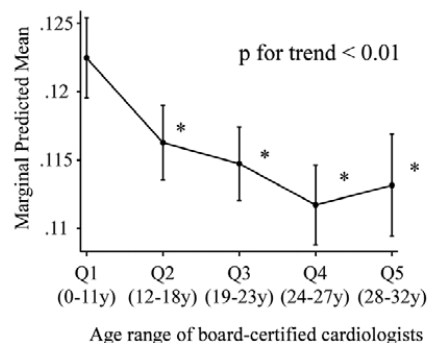

$\mathrm{E}$

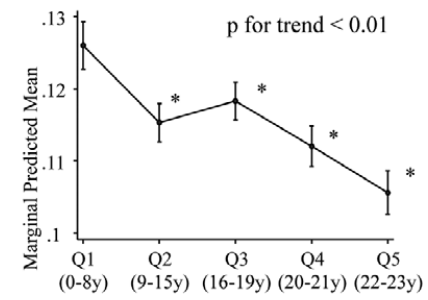

Range of years of experience as board-certified cardiologists
$\mathrm{C}$

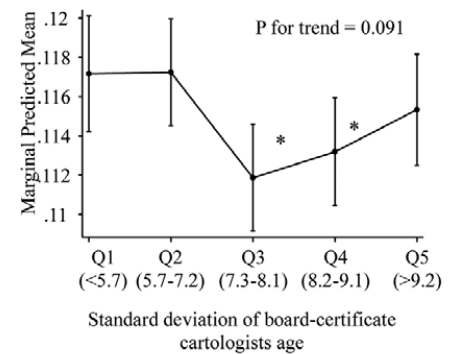

F

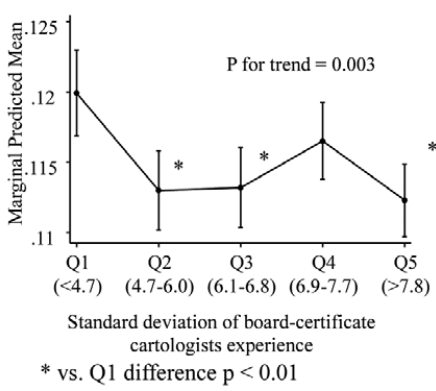

Figure 2. In-hospital mortality rates for cardiovascular disease vs. quintiles of $(\mathbf{A})$ age, (B) age range, (C) age SD, (D) years of experience, $(\mathbf{E})$ range of years of experience and $(\mathbf{F})$ SD of range of years of experience of board-certified cardiologists, on a per-institution basis. Bars, $95 \% \mathrm{Cl}$. Adjusted probability was calculated using the marginsplot command in STATA, and was adjusted as indicated in Table 2.

\section{Cardiologist Board Certification and In-Hospital Mortality}

The overall in-hospital mortality rate was $13.2 \%$. On multilevel mixed-effects logistic regression modeling (Table 2), the median age of the board-certified cardiologists per institution was not related to in-hospital mortality (OR, 1.003; 95\% CI: 0.998-1.008; $\mathrm{P}=0.316$ ), after adjusting for facility. A greater board-certified cardiologist age range at an institution, however, and a greater SD of age were found to be associated with a lower risk of in-hospital mortality (age range: OR, 0.992; 95\% CI: 0.988-0.995 per 1-unit increment in age range, $\mathrm{P}<0.001$; age $\mathrm{SD}$ : $\mathrm{OR}, 0.990 ; 95 \%$ CI: 0.982-0.999 per 1-unit increment in age range, $\mathrm{P}<0.05$ ), after adjusting for facility, patient clinical characteristics, and treatment. On a per-institution basis, board-certified cardiologist average years of experience were not associated with a lower risk of in-hospital mortality (OR, 1.002; 95\% CI: $0.996-1.007 ; \mathrm{P}=0.525)$. A greater range of boardcertified cardiologist years of experience at an institution, however, and a greater SD were found to be associated with a lower risk of respective in-hospital mortality (age range: 


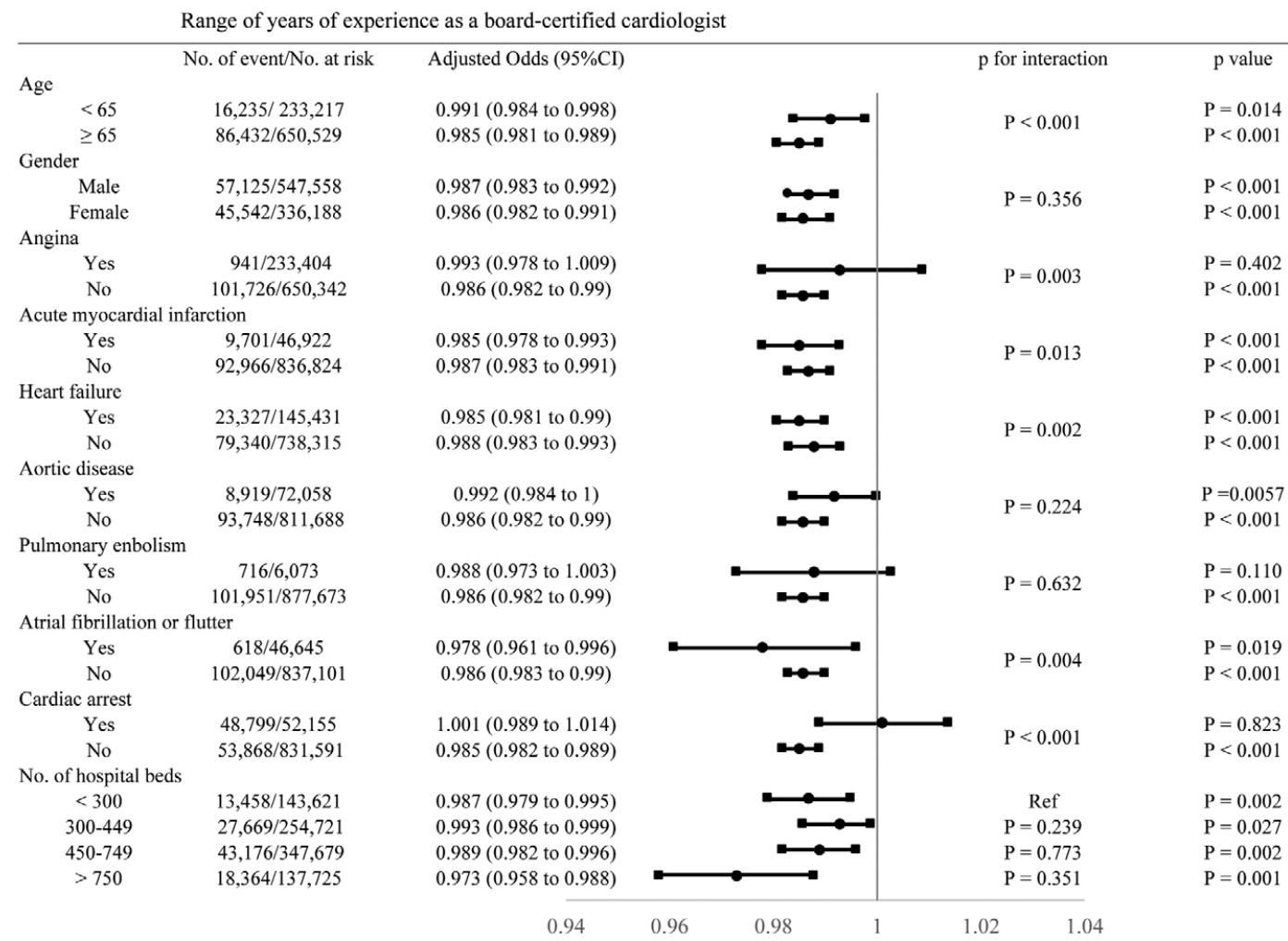

Figure 3. Adjusted $\mathrm{OR}$ and $95 \% \mathrm{Cl}$ for in-hospital mortality from cardiovascular disease according to board-certified cardiologist years of experience. OR $<1.0$ represents a decreased risk of in-hospital mortality as board-certified cardiologist years of experience increase. OR, dot; $95 \% \mathrm{Cl}$, lines. OR were adjusted for both facility and patient characteristics and treatment, as indicated in Table 2.

OR, 0.986; 95\% CI: 0.983-0.990, per 1-unit increment of years of experience, $\mathrm{P}<0.001$; age $\mathrm{SD}$ : $\mathrm{OR}, 0.982 ; 95 \% \mathrm{CI}$ : 0.973-0.992, per 1-unit increment in age range, $\mathrm{P}<0.001$ ), after adjusting for facility, patient clinical characteristics, and treatment.

The association between board-certified cardiologists and in-hospital mortality is shown in Figure 2. A non-linear association was observed across the quartile of boardcertified cardiologist age ( $\mathrm{P}$ for trend $=0.186$; Figure 2A) for in-hospital mortality, SD of age $(\mathrm{P}$ for trend $=0.091$, Figure 2C), and quartile of board-certified cardiologist years of experience ( $\mathrm{P}$ for trend $=0.187$; Figure 2D). A linear association was observed, however, across the quartile of board-certified cardiologist age range $(\mathrm{P}$ for trend $<0.01$; Figure 2B) for in-hospital mortality, and quartile of board-certified cardiologist range of years of experience ( $P$ for trend $<0.01$, Figure 2E), and SD of experience ( $P$ for trend=0.003; Figure 2F).

\section{Subgroup Analysis According to Heart Disease}

Analysis of the association between board-certified cardiologist years of experience and in-hospital mortality according to disease is shown in Figure 3. On multilevel mixed-effects logistic regression modeling, significant interactions were seen between board-certified cardiologist years of experience in an institution and respective patient age $(\mathrm{P}<0.001)$, angina $(\mathrm{P}=0.0030 ;$ myocardial infarction $(\mathrm{P}=0.013)$, heart failure $(\mathrm{P}=0.002)$, atrial fibrillation
$(\mathrm{P}=0.004)$, and cardiac arrest $(\mathrm{P}<0.001)$. There was no interaction effect, however, between board-certified cardiologist years of experience (on a per-institution basis), hospital volume, and in-hospital mortality.

\section{Discussion}

Data om 1,185 hospitals and 896,171 patients, sourced from the JROAD and JROAD-DPC databases, were analyzed in this study, making it one of the largest, cross-sectional, retrospective studies conducted to date on nationwide, in-hospital health outcomes. We found that the median age/experience of the board-certified cardiologists in an institution is not related to respective in-hospital mortality, but that a greater range of board-certified cardiologist age/ experience at an institution is associated with a lower risk of respective in-hospital mortality (Figure 4). This suggests that variation in board-certified cardiologist age/experience may have a meaningful impact on patient outcome.

Furthermore, in the present study median board-certified cardiologist age/experience at an institution was not related to respective in-hospital mortality. Patients treated by older physicians have been found to have higher mortality rates than patients treated by younger physicians. ${ }^{\mathbf{1 6}, 17}$ It has also been reported that invasive treatments performed by specialists result in lower mortality rates than do similar treatments performed by non-specialists. ${ }^{18,19}$ The present results are not consistent with those of previous studies. 


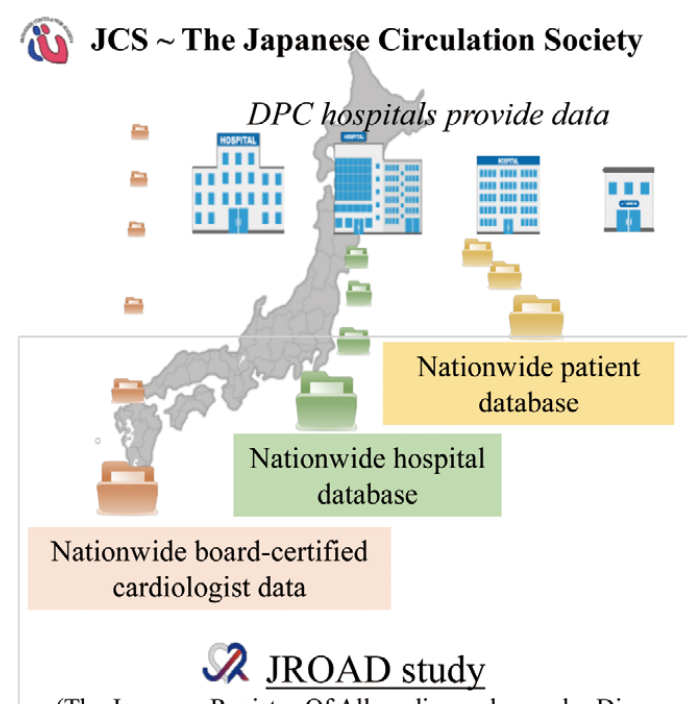

(The Japanese Registry $\underline{\text { Of }} \underline{\text { All cardiac and }}$ vascular Diseases)

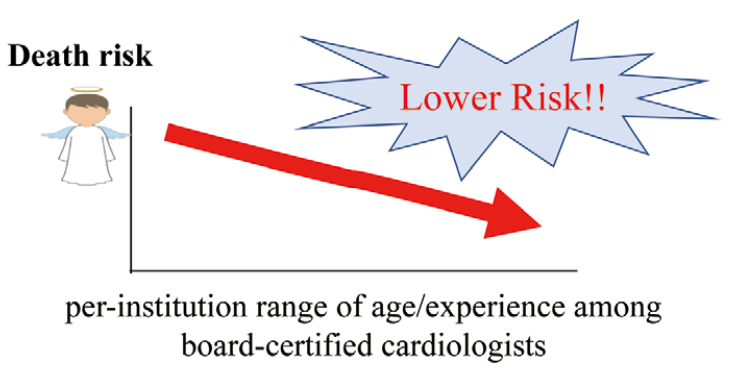

Not median age, but wider range of age
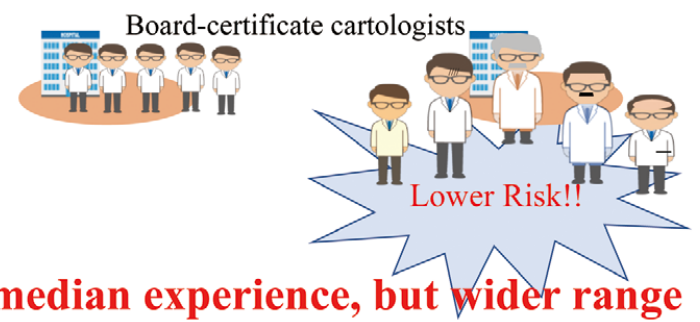

Not median exp
of experience

Figure 4. Summary of the present results. Data from the nationwide database of acute care hospitals in Japan, comprising 2,371 hospitals, were collected between 2012 and 2013. DPC, diagnostic procedure combination.

Compared with the previous reports, JROAD included only teaching hospitals and, in the present study, we included only board-certified physicians who have passed a specific exam of medical knowledge, clinical knowledge, and diagnosis skills. Burke et al reported that teaching hospitals were associated with lower mortality compared with nonteaching hospitals. ${ }^{20}$ Teaching hospitals are more likely to be higher volume centers and to provide more technologically intensive care requiring specialized knowledge, than nonteaching hospitals. ${ }^{20}$ Although physician age/experience may be an important factor for reducing the risk of patient death, other factors independent of physician age, such as special knowledge, skills, hospital volume, and attending professional training, have been confirmed to reduce the risk of patient death. ${ }^{19,18,21,22}$ Therefore, physicians working at major teaching hospitals are more likely to continue advancing their knowledge and utilize the most up-to-date standard practices for patient care.

The second finding in the present study was that institutions with a greater range of board-certified cardiologist age/experience have a lower risk of in-hospital mortality. Compared with younger physicians, physicians who have been practicing for a higher number of years and who are older possess less factual knowledge and are less likely to adhere to appropriate standards of care. ${ }^{17,23,24}$ In contrast, surgery mortality rates have been found to be lower for older surgeons than for younger surgeons. ${ }^{25}$ Although the present findings did not support those of previous studies, it may be hypothesized that if younger physicians have more up-to-date knowledge, and older physicians have more experience, then a combination of the two, as reflected in a wider range of age/experience per hospital, could lower the risk of in-hospital death. In contrast to previous studies, the present study provides new evidence that hospitals with a wide range of board-certified cardiologist age/experience can provide good medical care in cardiology.

Also, according to the present subgroup analysis, boardcertified cardiologist range of age/experience at an institution is associated with lower mortality rates for several diseases, excluding angina, pulmonary embolism (PE), and cardiac arrest. The regression models, after adjustment for patient characteristics, however, indicated that the latter 3 were indeed associated with a lower risk of in-hospital mortality. Given that the number of angina and PE cases was very small, these did not influence the result. Meanwhile, mortality rates concerning cardiac arrest have been found to be associated with, aside from hospital characteristics, shockable rhythm, patient age, time to cardiopulmonary resuscitation, and out-of-home events. ${ }^{\mathbf{2 6 - 2 9}}$ Thus, in institutions with high mortality rates, the influence of cardiac arrest may not be statistically significant.

\section{Study Limitations}

This study had several limitations. First, we included only DPC hospitals with cardiovascular beds that met JCS requirements; JROAD, however, is the largest crosssectional study of nationwide cardiac health outcomes in Japan. Second, evaluating only the association of boardcertified cardiologists with any cause of death was not possible, because JROAD does not have data on cause of death. Third, the prevalence of in-hospital death of patients with angina, PE, and atrial fibrillation was low. Fourth, although the analysis of median age/years of experience was limited due to the relatively small number of boardcertified cardiologists per hospital, this is the largest study yet to evaluate the association of board-certified cardiologists with in-hospital death, thus allowing for a unique investigation of the risk of death at a national level. 


\section{Implications for Clinical Care}

According to the present study, institutions with a greater range of board-certified cardiologist age/experience have a lower risk of in-hospital mortality. This suggests that the presence of a wide range of board-certified cardiologist age groups at a hospital is a benefit to clinical cardiac care (by preventing patient deaths), and that such diversity results in the cardiologists successfully maintaining competence and learning new skills and knowledge.

\section{Conclusions}

Median board-certified cardiologist age/experience at an institution is not related to in-hospital mortality, but greater board-certified cardiologist age/experience range is associated with a lower risk of in-hospital mortality.

\section{Acknowledgments}

The authors would like to thank Yoko Sumita, the other investigators, the hospital staff, and the participants of the JROAD study for their valuable contributions. A full list of participating institutions can be found at http://jroadinfo.ncvc.go.jp

\section{Author Contributions}

M.W. and K.Y. contributed equally to this work. The corresponding author attests that all listed authors meet authorship criteria and that no others meeting the criteria have been omitted.

\section{Disclosures}

K.Y. has received personal fees from Sanofi. Y.S. has received personal fees from Mitsubishi Tanabe Pharma Corporation, Otsuka Pharmaceutical, Novartis Pharma, Amgen Astellas BioPharma, Terumo Corporation, Astellas Pharma, Takeda Pharmaceutical, Teijin Pharma, Bayer Holding, Daiichi Sankyo, and MSD. K.N. has received personal fees from Mitsubishi Tanabe Pharma, Fillips Japan Corporation, and Tokyo Energy Holdings. Y.M., S.Y., T.M., and Y.J.A. are members of Circulation Reports' Editorial Team. The other authors declare no conflicts of interest.

\section{References}

1. Ford ES, Ajani UA, Croft JB, Critchley JA, Labarthe DR, Kottke TE, et al. Explaining the decrease in U.S. deaths from coronary disease, 1980-2000. N Engl J Med 2007; 356: 2388-2398.

2. Lozano R, Naghavi M, Foreman K, Lim S, Shibuya K, Aboyans $\mathrm{V}$, et al. Global and regional mortality from 235 causes of death for 20 age groups in 1990 and 2010: A systematic analysis for the Global Burden of Disease Study 2010. Lancet 2012; 380: 2095 2128.

3. Packer M, Bristow MR, Cohn JN, Colucci WS, Fowler MB, Gilbert EM, et al. The effect of carvedilol on morbidity and mortality in patients with chronic heart failure: U.S. Carvedilol Heart Failure Study Group. N Engl J Med 1996; 334: 1349-1355.

4. Ide T, Ohtani K, Higo T, Tanaka M, Kawasaki Y, Tsutsui H. Ivabradine for the treatment of cardiovascular diseases. Circ J 2019; 83: 252-260.

5. Cho KI, Sakuma I, Sohn IS, Hayashi T, Shimada K, Koh KK. Best treatment strategies with statins to maximize the cardiometabolic benefits. Circ J 2018; 82: 937-943.

6. Marume K, Takashio S, Nagai T, Tsujita K, Saito Y, Yoshikawa T, et al. Effect of statins on mortality in heart failure with preserved ejection fraction without coronary artery disease: Report from the JASPER study. Circ J 2019; 83: 357-367.

7. Bellotti P, Badano LP, Acquarone N, Griffo R, Lo Pinto G, Maggioni AP, et al. Specialty-related differences in the epidemiology, clinical profile, management and outcome of patients hospitalized for heart failure; the OSCUR study: Oucome dello Scompenso Cardiaco in relazione all'Utilizzo delle Risore. Eur Heart J 2001; 22: 596-604.

8. Philbin EF, Weil HF, Erb TA, Jenkins PL. Cardiology or primary care for heart failure in the community setting: Process of care and clinical outcomes. Chest 1999; 116: 346-354.

9. Kanaoka K, Okayama S, Yoneyama K, Nakai M, Nishimura K,
Kawata $\mathrm{H}$, et al. Number of board-certified cardiologists and acute myocardial infarction-related mortality in Japan: JROAD and JROAD-DPC registry analysis. Circ J 2018; 82: 2845-2851.

10. Yasuda S, Nakao K, Nishimura K, Miyamoto Y, Sumita Y, Shishido T, et al. The current status of cardiovascular medicine in Japan: Analysis of a large number of health records from a nationwide claim-based database, JROAD-DPC. Circ J 2016; 80: $2327-2335$.

11. Yasuda S, Miyamoto Y, Ogawa H. Current status of cardiovascular medicine in the aging society of Japan. Circulation 2018; 138: $965-967$

12. Yasunaga H, Ide H, Imamura T, Ohe K. Impact of the Japanese diagnosis procedure combination-based payment system on cardiovascular medicine-related costs. Int Heart J 2005; 46: 855 866.

13. Nakamura K. Diagnosis procedure combination database would develop nationwide clinical research in Japan. Circ J 2016; 80: $2289-2290$

14. Yasunaga H, Matsui H, Horiguchi H, Fushimi K, Matsuda S. Application of the diagnosis procedure combination (DPC) data to clinical studies. J UOEH 2014; 36: 191-197 (in Japanese).

15. Iihara K, Nishimura K, Kada A, Nakagawara J, Toyoda K, Ogasawara K, et al. The impact of comprehensive stroke care capacity on the hospital volume of stroke interventions: A nationwide study in Japan: J-ASPECT study. J Stroke Cerebrovasc Dis 2014; 23: $1001-1018$.

16. Choudhry NK, Fletcher RH, Soumerai SB. Systematic review: The relationship between clinical experience and quality of health care. Ann Intern Med 2005; 142: 260-273.

17. Tsugawa Y, Newhouse JP, Zaslavsky AM, Blumenthal DM, Jena AB. Physician age and outcomes in elderly patients in hospital in the US: Observational study. BMJ 2017; 357: j1797.

18. Badheka AO, Patel NJ, Grover P, Singh V, Patel N, Arora S, et al. Impact of annual operator and institutional volume on percutaneous coronary intervention outcomes: A 5-year United States experience (2005-2009). Circulation 2014; 130: 1392-1406.

19. Curtis JP, Luebbert JJ, Wang Y, Rathore SS, Chen J, Heidenreich PA, et al. Association of physician certification and outcomes among patients receiving an implantable cardioverter-defibrillator. JAMA 2009; 301: 1661-1670.

20. Burke LG, Frakt AB, Khullar D, Orav EJ, Jha AK. Association between teaching status and mortality in US hospitals. JAMA 2017; 317: 2105-2113.

21. Bertomeu V, Cequier A, Bernal JL, Alfonso F, Anguita MP, Muniz J, et al. In-hospital mortality due to acute myocardial infarction: Relevance of type of hospital and care provided. RECALCAR study. Rev Esp Cardiol (Engl Ed) 2013; 66: 935942.

22. Jong P, Gong Y, Liu PP, Austin PC, Lee DS, Tu JV. Care and outcomes of patients newly hospitalized for heart failure in the community treated by cardiologists compared with other specialists. Circulation 2003; 108: 184-191.

23. Salem-Schatz SR, Avorn J, Soumerai SB. Influence of clinical knowledge, organizational context, and practice style on transfusion decision making: Implications for practice change strategies. JAMA 1990; 264: 476-483.

24. Golden NH, Seigel WM, Fisher M, Schneider M, Quijano E, Suss A, et al. Emergency contraception: Pediatricians' knowledge, attitudes, and opinions. Pediatrics 2001; 107: 287-292.

25. Tsugawa Y, Jena AB, Orav EJ, Blumenthal DM, Tsai TC, Mehtsun WT, et al. Age and sex of surgeons and mortality of older surgical patients: Observational study. BMJ 2018; 361: k1343.

26. Callaway CW, Schmicker R, Kampmeyer M, Powell J, Rea TD, Daya MR, et al. Receiving hospital characteristics associated with survival after out-of-hospital cardiac arrest. Resuscitation 2010; 81: 524-529.

27. Ballesteros-Pena S, Abecia-Inchaurregui LC, Echevarria-Orella E. Factors associated with mortality in out-of-hospital cardiac arrests attended in basic life support units in the Basque Country (Spain). Rev Esp Cardiol (Engl Ed) 2013; 66: 269-274.

28. Nakashima T, Noguchi T, Tahara Y, Nishimura K, Ogata S, Yasuda S, et al. Patients with refractory out-of-cardiac arrest and sustained ventricular fibrillation as candidates for extracorporeal cardiopulmonary resuscitation: Prospective multi-center observational study. Circ J 2019; 83: 1011-1018.

29. Kiyohara K, Sado J, Kitamura T, Ayusawa M, Nitta M, Iwami $\mathrm{T}$, et al. Epidemiology of pediatric out-of-hospital cardiac arrest at school: An investigation of a nationwide registry in Japan. Circ J 2018; 82: 1026-1032. 